\title{
Notochordal Tumor
}

National Cancer Institute

\section{Source}

National Cancer Institute. Notochordal Tumor. NCI Thesaurus. Code C7063.

A bone tumor arising from the remnants of the fetal notochord. This category includes the chordoma and benign notochordal cell tumor. 